\title{
PERIPHERAL ULCERATIVE KERATITIS AS THE FIRST MANIFESTATION OF RHEUMATOID ARTHRITIS - CASE REPORT
}

Danielly Dantas Pimentel ${ }^{1}$,, , Taisa Morete da Silva ${ }^{1}$, Iane Tamara Donde ${ }^{1}$, Patricia Milani de Moraes ${ }^{1}$, Carlos Augusto Rodrigues Padilha $^{1}$, Juliana de Jesus Boscolo ${ }^{1}$, Renata Vaz de Oliveira ${ }^{1}$, Gustavo Roberto Lourenço ${ }^{1}$, Maria Juliana da Silva Almeida ${ }^{1}$

1.Faculdade de Medicina de São José do Rio Preto, São José do Rio Preto (SP), Brazil.

*Corresponding author: daniellydantas2011@gmail.com

\section{BACKGROUND}

Rheumatoid arthritis (RA) is a common and chronic systemic inflammatory disease of unknown etiology that mainly involves the joints. It can present with extra-articular manifestations, like ophthalmic involvement, including peripheral ulcerative keratitis (PUK), which is an inflammatory disease of the periphery of the cornea and sclera, with self-limited episodes to rapidly progressive and destructive processes

\section{CASE REPORT}

Female, 66 years old, started ocular pain, pruritus, hyperemia and edema on the left, which was evidenced in an ophthalmological exam with hyperemic conjunctiva, with a peripheral lower lesion, ulcerated and irregular, in addition to opacity with an area of significant lower tapering and lower nourishing vessel. The hypothesis of PUK was raised. After 6 months of this clinical picture, the patient evolved with polyarthritis, increased inflammatory tests, high titers of rheumatoid factor and anti-CCP, being then diagnosed with rheumatoid arthritis and started rheumatologic follow-up.

\section{CONCLUSION}

Most connective tissue diseases can produce ocular manifestations; however, when ulcerative keratitis occurs, a group of diseases including rheumatoid arthritis, granulomatosis with polyangiitis, recurrent polychondritis, polyarteritis nodosa and systemic lupus erythematosus should be investigated. Among these diseases, rheumatoid arthritis is the most common, affecting about $1 \%$ of the general population and, of these, approximately $25 \%$ will present ocular complications at some point during the course of the disease, with PUK being diagnosed in $34 \%$ of cases, which is characterized by stromal opacity and variable degrees of vascularization and corneal thinning in perilimbal crescents. Peripheral ulcerative keratitis can occur as the first manifestation of autoimmune diseases in $50 \%$ of cases, requiring the exclusion of infectious causes. Patients often complain of decreased visual acuity, photophobia, and foreign body sensation. Despite being infrequent, the patient started the condition with an ocular manifestation, and later evolved with a joint condition, being referred to a rheumatologist for monitoring of the disease and appropriate treatment.

\section{KEYWORDS}

Arthritis, Ulcerative keratitis, Inflammatory disease. 